\title{
Information and Communication Technologies Adoption in Small Firms
}

\author{
Rodrigo Fernandes Malaquias ${ }^{1}$ \\ Fernanda Francielle de Oliveira Malaquias ${ }^{2}$
}

\begin{abstract}
Information and Communication Technologies (ICTs) can provide a set of benefits to companies, such as efficiency gains in managerial activities, cost reduction and faster communication with consumers. The ICT literature has studies showing the positive impact that the IT adoption can generate on the company's performance. ICT benefits are also extensive to small business, but their particular characteristics do not always support their adoption by these enterprises, especially when they are enterprises situated in developing countries. In this context, the aim of this paper was to identify how the ICT adoption and the ICT intention of use are in Brazilian small firms. We have used a case study and we have collected data from four enterprises. In order to collect the data, we used qualitative interviews, direct observation and documental analysis. The main results have shown that the owner's characteristics, the understanding of the ICT benefits, the ICT complexity and the costs/time related to training people are factors associated with the ICT adoption and intention of use. Based on the literature review and on the empirical evidence, we have found that there is an opportunity cost related to postponing the decision of the ICT investments. We also discuss the role of geographical localization of the enterprises, which can contribute to the ICT literature.
\end{abstract}

Keywords: ICT Adoption. Owner Characteristics. Human Behavior. Small Enterprises. Opportunity Cost.

$$
* * *
$$

\section{Introduction}

It is undeniable that the use of Information and Communication Technology (ICT) can provide several benefits to organizations. The potential benefits that can be obtained by an organization when adopting the ICT involve efficiency gains in administration, control and

\footnotetext{
${ }^{1}$ Faculdade de Gestão e Negócios da Universidade Federal de Uberlândia, Brasil. ORCID: http://orcid.org/0000-0002-7126-1051 E-mail: rodrigofmalaquias@ufu.br

${ }^{2}$ Faculdade de Gestão e Negócios da Universidade Federal de Uberlândia, Brasil. ORCID: https://orcid.org/0000-0001-7997-530X E-mail: fernandafrancielle@gmail.com
} 
accountability, improvement of internal processes, cost reduction, elimination of double effort, greater access to information and faster communication with customers (Fink, 1998; Salmeron \& Bueno, 2006; Ongori \& Migiro, 2010; Kannabiran \& Dharmalingam, 2012; Giotopoulos, Kontolaimou, Korra \& Tsakanikas, 2017).

In addition, information technology facilitates the activities of storage, processing and distribution of information (Giotopoulos et al., 2017), by presenting a pivotal role in every kind of businesses (Eze \& Chinedu-Eze, 2018). In this sense, ICT can generate advantages for organizations of any size and in every sector (Fink, 1998; Federici, 2009). There are also contemporary innovations, such as cloud computing that enables "convenient, ubiquitous and on-demand access to computing resources" (AlBar \& Hoque, 2019, p. 150) and social networks that have changed the way organizations and customers interact, enabling a two-way communication (Tajudeen, Jaafar \& Ainin, 2018). It is important to note that there is a kind of opportunity cost when companies decide to postpone investments in ICT (Malaquias \& Albertin, 2011).

Although the ICT use cannot be exclusively applicable in the context of large business, small enterprises have not been adopting ICTs in the same extent as the large ones have (Sadowski, Maitland \& van Dongen, 2002; Zilber \& Araújo, 2012). The explanations for this lower rate of adoption rely mainly on the lack of knowledge and skills necessary for using information technologies, as well as on the barriers caused by financial constraints. The above mentioned explanations will be discussed in the following paragraphs.

Concerning the lack of knowledge and necessary skills to use ICTs, Tan, Chong, Lin \& Eze (2010) state that the main factors related to a lower level of technology adoption are the lack of technical skills and the lack of vision about the usefulness / benefits of technology (Tan et al., 2010). The lack of knowledge on advanced softwares and problems with infrastructure 
were also presented by previous research (Mbonyane \& Ladzani, 2011) in the context of small firms and they can affect technology adoption.

Regarding the financial constraints, Small and Medium Enterprises (SMEs) face a lot of financial barriers, especially in developing countries (Zorpas, 2010). These businesses "frequently have difficulties in obtaining capital or credit, particularly in the early start-up phase. Their restricted resources may also reduce access to new technologies or innovation" (Zorpas, 2010, p. 1546). Mbuyisa and Leonard (2017) also observed that many challenges imposed to small businesses affect their adoption of information technology.

In addition to the financial and technological barriers, the owners usually participate in all procedures and they play a central role in making decisions in smaller businesses (Mintzberg, 1979). Therefore, according to Zondi (2017), the owner must clearly comprehend the main process and objectives of the firm. As some owners can consider that most procedures are simple and do not take much of their time, they may decide to postpone the investments in ICTs. According to Thong (1999), the complexity of the technology perceived by the owner also negatively affects the intention to adopt information technology. The introduction of new technology in the context of a small business requires that both (business and technology) adapt to each other (Linton \& Solomon, 2017).

In Brazil, as in many other developing and developed countries, the small businesses represent one of the main engines of the economy development (Poon \& Swatman, 1999; Zorpas, 2010; Mbonyane \& Ladzani, 2011; Carvalho \& Malaquias, 2012; Zilber \& Araújo, 2012). Data from the Brazilian Micro and Small Business Support Service (2014) - SEBRAE shows that there are about 9 million micro and small enterprises in Brazil, which represent more than $98 \%$ of the total number of enterprises.

Due to the relevance of the small enterprises, a large number of ICT studies have focused on them (Sadowski et al., 2002; Zorpas, 2010; Cragg, Caldeira \& Ward, 2011). However, there is a lack of ICT studies with focus 
on small businesses in Latin American developing countries (Barbosa \& Musetti, 2010; Zilber \& Araújo, 2012). In this context, the aim of this paper is to identify how the ICT adoption and the ICT intention of use are in Brazilian small enterprises. To do so, we have used the case study research strategy (Eisenhardt, 1989), in which we choose four Brazilian enterprises to develop our discussion. As secondary objectives, we intend to: (i) analyze potential barriers related to ICT adoption in the context of small enterprises; and (ii) identify some potential opportunity costs related to the postponement of ICT adoption. The empirical analysis is segregated in four subtopics, based on Thong (1999): owner characteristics, ICT characteristics, organizational characteristics and environmental characteristics.

This issue is important for the academics and for the managers and owners of SMEs. For academics, there is a theoretical framework (that studies and tries to explain) the ICT adoption and ICT intention of use by SMEs. The inclusion of new data and new discussion in this field can contribute with future research and with future practices by the companies. Based on the arguments made by Mbonyane and Ladzani (2011), we believe that the inclusion of the particularities of developing countries in the academic papers can generate a positive effect for these markets. Moreover, challenges and opportunities related to ICTs are different between large firms and SMEs (Salleh, Rohde \& Green, 2017), which reinforces the relevance of conducting an analysis about information technology in the context of small firms.

\section{Literature Review}

\subsection{Small Businesses}

As stated by Mbuyisa and Leonard (2017), the socioeconomic growth contribution provided by small businesses has been recognized by academic literature. Several authors have described the main characteristics of small businesses: they are usually family-based; they have very "low 
management"; they operate in a highly competitive environment; they have little access to the new requirements of the market; they are susceptible to external forces; among others (Gable, 1991; Thong, 1999; Zorpas, 2010; Zilber \& Araújo, 2012). Small firms are not simply large companies in a small scale, because the characteristics of these enterprises are quite different (Zilber \& Araújo, 2012).

Evidence from literature suggests that SMEs in developing countries face multiple challenges, e.g. lack of access to finance, lack of skills and poor infrastructure. To minimize the challenges, several solutions have been suggested, including the adoption of ICTs to boost efficiency and competitiveness (Mbuyisa \& Leonard, 2017, p.191).

As it happens to small enterprises, large companies also face constraints and difficulties in their daily activities. However, these constraints and difficulties are more intense in small enterprises (Thong, 1999). The challenges imposed to small business include lack of financial resources; lack of human resources; unsuitability for the type of the business; security and trust of ICT; lower understanding about ICT benefits (Salmeron \& Bueno, 2006; Ongori \& Migiro, 2010). The absence of a longterm planning is also a characteristic of SMEs, due to their short-term vision. "As a result, owners are often hesitant to make substantial investments when short-term returns are not guaranteed" (Migiro \& Ocholla, 2005, p. 292).

\subsection{Information Technology Adoption in Small Businesses}

Information Technology (IT) can be defined as "computer-based technology for the storage, accessing, processing and communication of information" (Molloy \& Schwenk, 1995, p. 283). The adoption of ICTs for SMEs is a critical factor for their survival (Ongori \& Migiro, 2010; Mehrtens, Cragg \& Mills, 2001; Ongori \& Migiro, 2010; Awiagah, Kang \& Lim, 2016), since globalization requires companies to expand systems and 
communicate with the global economy (Hwang \& Grant, 2016). Therefore, there has been an increase in the number of studies about the adoption of information technology by small and medium-sized firms in the past years (Salleh, Rohde \& Green, 2017).

For example, with e-commerce, the enterprise can overcome geographical limitations and the whole world becomes accessible, which can reduce travel time and costs (Mbatha, 2013). However, there are different internal and external factors that influence information technologies and, more specifically, e-commerce technology adoption by small business that may influence the benefits these enterprises gain by using such technologies (Kartiwi, Hussin, Suhaimi, Jalaldeen \& Amin, 2018). Internal factors include size, level of Internet use and these enterprises own characteristics (Kabanda \& Brown, 2017; Kartiwi et al., 2018). External factors include market forces, legal structure and government (Kabanda \& Brown, 2017; Kartiwi et al., 2018).

Most challenges faced by small enterprises are common everywhere (Mbonyane \& Ladzani, 2011). However, particularly in developing countries, these businesses face a lot of stifling financial and regulatory constraints (Zorpas, 2010). In order to analyze the factors related to the use of information technology in small business, we used the four dimensions adopted by Thong (1999): owner characteristics, ICT characteristics, organizational characteristics and environmental characteristics. Besides having used these four dimensions, we include some sub-dimensions in each characteristic, because we have analysed other papers (such as: Mehrtens et al., 2001; Ongori \& Migiro, 2010; Cragg et al., 2011; Malaquias \& Albertin, 2011; Hwang \& Grant, 2014; Awiagah et al., 2016; Kabanda \& Brown, 2017; Kartiwi et al., 2018) published after Thong's research.

In SMEs, "the central role of the CEO suggests that the characteristics of the CEO are even more critical in the decision of small business to adopt IS" (Thong, 1999, p. 188). This argument of Thong (1999) is in accordance with Mahrtens et al. (2001), when the authors state that 
the owner has a significant role in the ICT adoption among SMEs. Thus, the personal characteristics of the owner tend to affect the intention of use ICTs (Mpofu \& Watkins-Mathys, 2011; Kannabiran \& Dharmalingam, 2012). In such a context, even though it is a complex issue, it is worth mentioning that ICT use can contribute to the performance of SMEs in dynamic settings (Neirotti, Raguseo \& Paolucci, 2018).

The owner characteristics involve technological knowledge, necessary skills to use ICT and understanding ICT benefits. Previous studies (Fink, 1998; Ongori \& Migiro, 2010; Kannabiran \& Dharmalingam, 2012) support that these characteristics (knowledge, skills and understanding related to ICT benefits) have a positive relationship with the ICT adoption. As to the ICT characteristics, the complexity of the technology plays an important role in the ICT adoption. According to Thong (1999), there is a negative relationship between the technology complexity perceived by the owner and the intention of adopting ICT. If the new technology is "not perceived as beneficial to the small business, there is no reason to adopt" it (Thong, 1999, p. 208).

Migiro and Ocholla (2005), with a sample of 57 tourism SMEs service providers from Durban (South Africa), found that the main barriers to ICT adoption were higher costs involved in this adoption and limited financial resources. The limited resources (financial, technical, human, equipment) are part of the organizational characteristics. Fink (1998), with a sample of 87 SMEs from Western Australia, found that internal characteristics of the enterprises were significant on ICT adoption. The presence of products that are intensive in technology can also affect the intention regarding ICT investments (Thong, 1999).

Due to limited resources (financial, human and technical), SMEs generally adopt packaged software (Gable, 1991; Chau, 1995). In this regard, it is important that the package meets the needs of the enterprise, as well as the vendor needs to provide the company with adequate support. "ERP increases company performance but piecemeal implementation leads 
to isolated islands of ERP technologies that reduce performance" (Hwang \& Grant, 2014, p. 6). Upadhyay, Jahanyan \& Dan (2011) reported some agency problems in their study, in which some vendors sold packages on which they did not have the necessary knowledge to deliver. The consequences were ineffectiveness in the packaged software and, after the implementation; the investments were treated as sunk costs.

\section{Method}

According to Eisenhardt (1989), case studies can involve a single case or multiple ones and they can combine data collection methods. In case studies, the selection of the cases is an important aspect, once theoretical reasons need to support the choice (Eisenhardt, 1989). With regard to case studies, Yin (2009) states that they are preferred when we have proposed questions such as "how" and "why", which is the case of this study.

Thus, after the theoretical revision, we identified an opportunity to develop a new research about ICT adoption in small enterprises situated in Brazil. Since the aim is to identify the ICT adoption and the ICT intention of use in Brazilian small firms, we consulted some small enterprises that would have availability to participate in this research within our network.

After the contacts, we chose four small businesses, and the owners agreed to participate in the study. These firms operate in the sectors of retail business, games, snack bar and roast beef/chicken and they were chosen due to their size (small business); their owners also develop operational tasks and three of them have been operating in the market for more than twenty years. Therefore, four individuals (the owners of the small businesses) were invited to participate in the research and they accepted it. These enterprises operate in the Southeast region of Brazil and their owners and employees are Brazilian. In all four cases, the owners are involved in the operational activities of their respective business.

The four enterprises selected for this study are formally constituted and some additional information on them are presented in the following 
items: (i) Enterprise A (Owner A) has two individuals involved in the business and it has among 1,000 products included in its portfolio to negotiate/sell and it started in 1999 - This company does not have a computer; (ii) Enterprise B (Owner B) has six individuals involved in the business, and it has among 12 products included in its portfolio to negotiate/sell and it started in 1987; (iii) Enterprise C (Owner C) has 12 individuals involved in the business, and it has among 130 products included in its portfolio to negotiate/sell and it started in 1992; and (iv) Enterprise D (Owner D) has five individuals involved in the business and it has among 12 products included in its portfolio to negotiate/sell and it started in 2010. This enterprise is in discontinuity process.

The owners of Enterprise C purchased it in 1992. At that time, the enterprise had many problems, especially in the services provided to the customers. Thus, in that year, the owners completely restructured the business. The companies A, B and D started their business with few products and with a very simple structure. None of them has a strategic planning for the next years.

The enterprises have basic technologies such as fixed telephone, mobile phones, and credit card terminals, but Enterprise A does not have internet access, as well as computers. The other three observed enterprises have computers with internet access and Enterprise $\mathrm{C}$ provides Wi-Fi access to their customers.

We considered that our selection was in line with the theoretical needs that we had presented, satisfying the recommendations of Eisenhardt (1989): (i) we selected small business; (ii) in all cases the owners are also the managers and they develop operational tasks; (iii) the four cases are from Brazil and involve Brazilian owners/employees; and (iv) three of the enterprises have been operating in the market for more than twenty years.

In the present study, we used different methods to collect data, once we intended to make the triangulation (Yin, 2009). Eisenhardt (1989) states that the triangulation can provide stronger substantiation to case studies. 
Thus, to collect the data, we used three methods: interviews, that is one of the most important sources of information of case studies (Yin, 2009); direct observation; and documental analysis. The following five paragraphs summarized the details on our data collection and on data analysis.

The first stage of the data collection was the direct observation. To do so, we visited each enterprise and we produced annotations about the available items related to ICT; the organization of the products at the enterprises; the general layout (intern and extern); the interaction with customers; the interactions between the employees and the owners; the operational tasks developed by the owners; the existence and the practice of control procedures; among others. This stage was important to analyze the cases and to help us with the developing of the interview guide.

In the second stage, we interviewed the owners of each enterprise. In order to develop the first version of the interview guide, we used the studies available in the theoretical revision of this paper (mainly the following: Fink, 1998; Thong, 1999; Mehrtens et al., 2001; Salmeron \& Bueno, 2006; Ongori \& Migiro, 2010; Tan et al., 2010; Mpofu \& Watkins-Mathys, 2011; Kannabiran \& Dharmalingam, 2012). Therefore, the interview guide contains items related to the four dimensions of Thong (1999) and also related ITCs and cost management, inventory control, geographical localization, potential incentives from government, tax issues, financial management, payment of bills before the due date, among many others. We analyzed the first version of the interview guide in the light of the annotations of the direct observation and, after the inclusion of additional items; we used its final version with 57 major questions and their subquestions. Many items are "open questions", which give the respondent the opportunity to express his/her perception related to the respective item and, at the same time, it allows the researcher to get more details regarding some aspects that appear during the data collection.

The interviews were performed in the year of 2015, in the local idiom (Brazilian Portuguese) and the answers were transcribed by using text- 
processing software. In order to analyze the content of the interviews, we used the content analysis procedure proposed by Bardin (2011). More specifically, based on the content of the interviews, we selected the "units of analysis" which were codified and, then, they were assigned to four categories. These four categories were established according to the theoretical framework: owner characteristics; ICT characteristics; organizational characteristics; and environmental characteristics (Thong, 1999).

During the interviews, some owners said that they use the internet as a marketing tool in order to reach new customers. Thus, through free online search portals, we checked the presence of the enterprises on the internet and collected the available online information. We recorded these results as PDF files and we used them in the documental analysis.

In order to build the discussion of the results, we used all the data that we collected through the interviews, direct observation and online search about the enterprise information. To organize the discussion, we employed the four categories of the content analysis. Finally, we compared the findings of the current research with the authors that have grounded our study.

\section{Results and Discussion}

As we explained before, the content analysis of the interviewees' responses resulted in four categories, based on Thong (1999), which were used to present our results and to build the discussion: owner characteristics; ICT characteristics; organizational characteristics; and environmental characteristics.

\subsection{Owner Characteristics}

One of the owners (Owner A) informed during the interview that she does not use computers and she does not carry out any operations by using the internet. She also said that she does not like to use computers in her 
personal activities and that there was not a computer in her enterprise. When we asked the owners about the interest in investing in a new ICT that fits their enterprise's needs, only Owner A said that this investment could wait.

The other owners have already made some purchases through the internet (as informed during the interviews). They generally use the internet to choose new products and opportunities both for the enterprise and for personal purposes. Their enterprises (B, C and D) have one computer at least. Among the four cases, Owner B is the only one that uses social networks as a marketing channel and his enterprise provides Wi-Fi access to customers.

In the interviews, some managers (B, C and D) informed that they use the internet as a marketing channel in order to improve sales. Owner B said that after adopting some actions to advertise the enterprise on the internet, most customers have contacted him. He said that the deal is more effective in these cases, once the customer had probably made a previous analysis of other companies. Mbatha (2013) considers that the e-commerce adoption can eliminate costs and time related to travel, which we also observed in our cases because owner B said that when a customer contacts the enterprise through the information available on the internet, he does not need to travel long distances to find the customer and they could negotiate via e-mail or telephone.

In the present paper theoretical framework, we have commented on the globalization and the enterprises's needs to expand their boundaries (Mehrtens et al., 2001; Ongori \& Migiro, 2010; Hwang \& Grant, 2016, Awiagah et al., 2016). Our results confirm the relevance of the presence of the companies on the internet, even if they are small companies.

We have searched the name of all enterprises on the internet. We did not find a specific website of companies B and C, but we found some details about these two enterprises in Brazilian group buying websites. As the owners of these two enterprises (during the interviews) informed that both 
were available to be consulted on the internet, we consider that they are underestimating the ICT benefits. Owners B and C experienced a positive result with the presence of their enterprises only in Brazilian group buying websites. If these enterprises had their own websites, we believe that the positive impact would be more intense.

The theoretical revision also shows that there is a relationship between understanding ICT benefits and ICT adoption (Fink, 1998; Ongori \& Migiro, 2010; Kannabiran \& Dharmalingam, 2012). Specifically for the enterprises $\mathrm{B}$ and $\mathrm{C}$, we found that the managers seem to undervalue the potential benefits of ICT adoption. According to Malaquias and Albertin (2011), when the companies do not adopt ICT in the level that they need, there is an opportunity cost of such decision. We considered that this opportunity cost is also applicable to the cases that we have discussed.

\subsection{ICT Characteristics}

Many authors have suggested that the ICT adoption should enhance the efficiency and the competitiveness of the enterprises (Fink, 1998; Salmeron \& Bueno, 2006; Ongori \& Migiro, 2010). According to Fink (1998) and Kannabiran and Dharmalingam (2012), ICT can help SMEs to improve internal processes as well as communication with customers. Migiro and Ocholla (2005) found that the majority of their survey respondents believes that the IT can provide internal efficiency.

In our study, the owners have recognized that ICT could help them in the business administration and control, which is according to the arguments of previous papers. On the other hand, the owners think that the benefits of ICT adoption will not cover its necessary costs and efforts. The owners have informed that another factor that affects their intention of investing in ICT is the need to establish codes for the products and register them in the system.

The considerations made by Thong (1999) seem to be applicable to this case, because the complexity about the technology perceived by 
owners/managers can generate a negative impact on the willingness to adopt it. Thus, despite the fact that the registration of all products could facilitate the management activities and the decision process, the owners prefer not to adopt the ICT tools.

Malaquias and Albertin (2011) found results for a Brazilian company by indicating that the owners expressed concern about the potential dependence on technology, after a potential full adoption of technology resources in the company. Nevertheless, it was not a concern among the owners that we interviewed (based on the data that we collected).

During the interviews, the owners did not disclose any discomfort related to ICT compatibility/incompatibility with the needs of their business. Owners $\mathrm{A}$ and $\mathrm{C}$ said that their main competitive firms use advanced ICT. Even in this case, they believe that the adoption of more advanced ICT will not necessarily bring a positive impact for their enterprise's profitability. This result indicates a strong association between the expected ICT benefits and the ICT adoption.

\subsection{Organizational Characteristics}

The owners' responses revealed that there is concern about the return of the resources that they could invest in ICT. Owners C and D said that the amount of financial resources represents a barrier for them to invest in ICT. They did not present any comment about restrictions to obtain credit; their concern involves the return of the investment, regardless of the source.

Perhaps, due to their short-term planning, the guarantee of shortterm return is really important for them. Migiro and Ocholla (2005) found that the main barriers to ICT adoption were higher costs and limited sources of resources. The authors also show that the absence of guarantee about short-term returns makes the owners hesitant about making higher investments in ICT. Our results were similar to the ones of Migiro and Ocholla (2005). 
The enterprises that we analyzed do not have a formal strategic planning and, in three cases (A, B and D), the owners informed that one of the reasons to postpone ICT investment is the need of training. Thus, they expect that the benefits that the ICT can provide to their enterprises will not cover the costs and the necessary time spent to train the employees. According to Gable (1991), Thong (1999), Ongori and Migiro (2010) and Cragg et al. (2011), small businesses are subject to a set of challenges such as lack of trained personnel. Our findings were in line with these studies, because the presence of employees with knowledge about these technologies could reduce the time spent in training and improve the intention of making ICT investments.

Enterprises $\mathrm{A}$ and $\mathrm{C}$ have shown the greatest internal layout and product disposal. Maybe the quantity of different products that they sell explains this observation. Since they do not have any computerized control, they need to organize the products in the best way to facilitate the search, the control and the supervision. Based on the theoretical review of this study (Giotopoulos et al., 2017; Eze \& Chinedu-Eze, 2018) and on the analysis of this research, we argue that information technology could improve the control procedures of the firms and facilitate the internal activities.

Owners $\mathrm{A}$ and $\mathrm{C}$ said that they check their stocks with a frequency of approximately six months. They also did not show any concerns about the possibility of losing some products or losing some sales due to the lack of a specific product. Malaquias and Albertin (2011) showed that one of the reasons that leads companies to postpone investments in ICT is the trust in the family structure that works in the company. In the case of these small enterprises, the owner's presence seems to replace the trust in a family structure. This owner's trust can contribute to the ICT investment postponement.

The enterprise, which has the highest use of ICTs (Enterprise C), is also the case that is most willing to make new ICT investments, despite the 
owner's concerns about the costs, the time spent to train employees, and the time spent to register all products. On the other hand, enterprise B has more information intensive products, because its music machine rental depends on the technology. This result is in accordance with the results of Thong (1999), as the author did not found a significant relationship between these two variables (information intensive products and ICT intention of use).

\subsection{Environmental Characteristics}

According to the literature review (Kabanda \& Brown, 2017; Kartiwi et al., 2018), we can observe that market forces also affect the adoption of information technology, and these forces include government incentives, for example. Regarding this point, the owners did not mention any government programs or incentives related to the adoption of ICT. They also did not disclose any concerns about the fact that their competitive firms are using more ICT than they are. In the interviews, based on the transcribed report, the words most frequently quoted were customer, cost, time, and customer's trust. One example of customer's trust refers to Enterprise B, which has serious concern about client credit risk. Furthermore, the control of the receivable accounts in this company is still manual.

The owner of Enterprise A said that one of the reasons that allows her to operate without using advanced ICT is the geographical localization of the business. Due to the localization of Enterprise A, people from the neighborhood can easily visit the enterprise, choose and buy with high frequency. The customers already know the owner and know the products that she sells. On the other hand, owner B said that if her enterprise were located in another place (for example, in a big mall), the ICT investment would be highly necessary.

When the owners considered the possibility of implementing an integrated Information System (IS), the general idea was to buy a package. This result is in accordance with Gable (1991) and Chau (1995), when the 
authors consider that, due the limited resources, SMEs usually buy packaged software developed by other companies. Thong (1999) states that the compatibility of the technology with the respective enterprise practices is a determinant factor to improve IT adoption.

However, Owner B said that all of his main competitive firms do not use IS to manage their enterprises. Enterprise B has been in the market for more than 20 years and, if there is no use of software in these companies, some questions arise: is it due to the decision of the owners (of not investing in IS) or is it due to the absence of supply? In another part of the interview, Owner B also said that, in the presence of an ICT that adequately fits his business, he would like to adopt it.

The diffusion and popularity of ERP systems, as stated by Federici (2009), represent the most relevant phenomenon in ICT sector. With ERP systems, the supplier can know the needs of its customer and implement a package that best meets such necessity. The appropriate implementation of ERP systems can improve business performance (Hwang \& Grant, 2016), once they are an integrated system (Galy \& Sauceda, 2014). This discussion leads us to think about opportunities for enterprises, that could adopt ERP, and for software suppliers, that could expand the implementation of ERP systems in the context of small firms.

Upadhyay et al. (2011) indicated that there was an increasing market for ERP adoption among Micro, Small and Medium-Sized Enterprises (MSME) in India. They reported that there are a lot of vendors who offer simplified and cheaper solution for these enterprises, but some of them fail in the product that they delivery. Their analysis, with MSMEs from India, indicated that the lack of proper expertise from the vendor was damaging the correct implementation of the ERP software.

\section{Conclusion}

According to the literature review, we can observe that ICT investments can provide benefits to small companies. Nevertheless, the 
constraints that are imposed to small companies, as well as their intrinsic characteristics, make their access to the ICT benefits difficult. This scenario can be more critical in developing countries. Within this context, we developed this study in order to identify how the ICT adoption and the ICT intention of use are in Brazilian small enterprises.

We selected four cases to analyze and to verify the adherence to the literature, so we were able to discuss and propose our contributions. After the interviews with the owners, the direct observation and the documental analysis, we found that the results from previous studies developed for small or SMEs, in general, were adherent to our cases. We observed that the main factors associated with the ICT adoption are owner's characteristics, the understanding about ICT benefits, the ICT complexity, and the costs/time related to training people. These results are also in line with previous literature, which indicates that internal and external factors affect the adoption of technologies (Kabanda \& Brown, 2017; Kartiwi et al., 2018).

Despite the intention of adopting ICTs, the owners would like to obtain some kind of guarantee that these investments will contribute to the business performance. Due to their short-term planning, the owners expect to have these returns in a short term. Without being sure about these returns, they prefer to postpone investments in ICTs.

Using the idea of Malaquias and Albertin (2011), there are opportunity costs related to the owner's decision about postponing ICT investments. One example of this opportunity cost is the number of customers that the enterprise could reach with the more intensive use of the internet. Hence, firms could improve their sales. Therefore, the enterprises should improve their ICT investment to be more competitive and expand their frontiers.

The geographical localization of the companies seems to take an important place for the decision in ICT investment. One of the owners said that if her company had another location in the same city, it would be very difficult to develop the activities without high ICT investments. Thus, we 
recommend future research that includes the control of the geographical location of the enterprises in the quantitative models.

We adopted the case study strategy to carry out our research. With the selected cases, we generated propositions that future research could test, but these propositions are not necessarily generalizable for all Brazilian small enterprises. We did not listen to the goods suppliers of each enterprise that we analyzed, as well as we only analyzed one company of each sector. Future research could expand these findings and concur with the theory development in this field.

\section{References}

AlBar, A. M., \& Hoque, M. R. (2019). Factors affecting cloud ERP adoption in Saudi Arabia: An empirical study. Information Development, 35(1), 150164. https://doi.org/10.1177/0266666917735677

Awiagah, R., Kang, J., \& Lim, J. I. (2016). Factors affecting e-commerce adoption among SMEs in Ghana. Information Development, 32(4), 815-836. https://doi.org/10.1177/0266666915571427

Barbosa, D. H., \& Musetti, M. A. (2010). Logistics information systems adoption: an empirical investigation in Brazil. Industrial Management \& Data System, 110(6), 787-804. https://doi.org/10.1108/02635571011055054

Bardin, L. (2011). Análise de Conteúdo. Lisbon: Edições 70.

Carvalho, C. J., \& Malaquias, R. F. (2012). Internal logistics, external communication, information processing and financial control: an analysis with Brazilian Micro and Small Enterprises. Journal of Operations and Supply Chain Management, 5(1), 31-44. https://doi.org/10.12660/joscmv5n1p31-44

Chau, P. Y. K. (1995). Factors used in the selection of packaged software in small business: views of owners and managers. Information \& Management, 29(2), 71-78. https://doi.org/10.1016/0378-7206(95)00016-P

Cragg, P., Caldeira, M., \& Ward, J. (2011). Organizational information systems competences in small and medium-sized enterprises. Information \& Management, 48(8), 353-363. https://doi.org/10.1016/j.im.2011.08.003 
Eisenhardt, K. M. (1989). Building theories from case study research. The Academy of Management Review, 14(4), 532-550. https://doi.org/10.5465/amr.1989.4308385

Eze, S. C., \& Chinedu-Eze, V. C. (2018). Examining information and communication technology (ICT) adoption in SMEs: A dynamic capabilities approach. Journal of Enterprise Information Management, 31(2), 338-356. https://doi.org/10.1108/JEIM-12-2014-0125

Federici, T. (2009). Factors influencing ERP outcomes in SMEs: a postintroduction assessment. Journal of Enterprise Information Management, 22(1/2), 81-98. https://doi.org/10.1108/17410390910922840

Fink, D. (1998). Guidelines for the successful adoption of information technology in small and medium enterprises. International Journal of Information Management, 18(4), 243-253. https://doi.org/10.1016/S0268$\underline{4012(98) 00013-9}$

Gable, G. G. (1991). Consultant engagement for computer system selection: a pro-active client role in small businesses. Information \& Management, 20(2), 83-93. https://doi.org/10.1016/0378-7206(91)90046-5

Giotopoulos, I., Kontolaimou, A., Korra, E., \& Tsakanikas, A. (2017). What drives ICT adoption by SMEs? Evidence from a large-scale survey in Greece. Journal of Business Research, 81(C), 60-69. https://doi.org/10.1016/j.jbusres.2017.08.007

Hwang, Y., \& Grant, D. (2016). An empirical study of enterprise resource planning integration: global and local perspectives. Information Development, 32(3), 260-270. https://doi.org/10.1177/0266666914539525

Kabanda, S., \& Brown, I. (2017). Interrogating the effect of environmental factors on e-commerce institutionalization in Tanzania: a test and validation of small and medium enterprise claims. Information Technology for Development, 23(1), 59-85. https://doi.org/10.1080/02681102.2016.1263593

Kannabiran, G., \& Dharmalingam, P. (2012). Enablers and inhibitors of advanced information technologies adoption by SMEs. Journal of Enterprise Information Management, $25(2)$ 186-209. https://doi.org/10.1108/17410391211204419

Kartiwi, M., Hussin, H., Suhaimi, M. A., Jalaldeen, M. R. M., \& Amin, M. R. (2018). Impact of external factors on determining E-commerce benefits among SMEs in Malaysia. Journal of Global Entrepreneurship Research, 8(1), 1-12. https://doi.org/10.1186/s40497-018-0105-7 
Linton, J. D., \& Solomon, G. T. (2017). Technology, Innovation, Entrepreneurship and The Small Business - Technology and Innovation in Small Business, Journal of Small Business Management, 55(2), 196-199. https://doi.org/10.1111/jsbm.12311

Malaquias, R. F., \& Albertin, A. L. (2011). Por que os gestores postergam investimentos em tecnologia da informação? Um estudo de caso. Revista de Administração Contemporânea, 15(6), 1120-1136. https://doi.org/10.1590/S1415-65552011000600009

Mbatha, B. (2013). Exploring the potential of electronic commerce tools in South African SME tourism service providers. Information Development, 29(1), 10-23. https://doi.org/10.1177/0266666912452270

Mbonyane, B., \& Ladzani, W. (2011). Factors that hinder the growth of small businesses in South African townships. European Business Review, 23(6), 550-560. https://doi.org/10.1108/09555341111175390

Mbuyisa, B., \& Leonard, A. (2017). The Role of ICT use in SMEs Towards Poverty Reduction: a Systematic Literature Review. Journal of International Development, 29(2), 159-197. https://doi.org/10.1002/jid.3258

Mehrtens, J., Cragg, P. B., \& Mills, A. M. (2001). A model of internet adoption by SMEs. Information \& Management, 39(3), 165-176. https://doi.org/10.1016/S0378-7206(01)00086-6

Migiro, S. O., \& Ocholla, D. N. (2005). Information and Communication Technologies in Small and Medium Scale Tourism Enterprises in Durban, South Africa. Information Development, 21(4), 283-294. https://doi.org/10.1177/0266666905060089

Mintzberg, H. (1979). The structure of organizations. Englewood Cliffs, NJ: Prentice Hall.

Molloy, S., \& Schwenk, C. R. (1995). The Effects of Information Technology on Strategic Decision Making. Journal of Management Studies, 32(3), 283311. https://doi.org/10.1111/j.1467-6486.1995.tb00777.x

Mpofu, K. C., \& Watkins-Mathys, L. (2011). Understanding ICT adoption in the small firm sector in Southern Africa. Journal of Systems and Information Technology, $\quad 13(2), \quad$ 179-199. https://doi.org/10.1108/13287261111136007

Neirotti, P., Raguseo, E., \& Paolucci, E. (2018). How SMEs develop ICTbased capabilities in response to their environment: Past evidence and 
implications for the uptake of the new ICT paradigm. Journal of Enterprise Information Management, 31(1), 10-37. https://doi.org/10.1108/JEIM-092016-0158

Ongori, H., \& Migiro, S. O. (2010). Information and communication technologies adoption in SMEs: literature review. Journal of Chinese Entrepreneurship, 2(1), 93-104. https://doi.org/10.1108/17561391011019041

Poon, S., \& Swatman, P. M. C. (1999). An exploratory study of small business Internet commerce issues. Information \& Management, 35(1), 9-18. https://doi.org/10.1016/S0378-7206(98)00079-2

Sadowski, B. M., Maitland, C., \& van Dongen, J. (2002). Strategic use of the Internet by small- and medium-sized companies: an exploratory study. Information Economics and Policy, 14(1), 75-93. https://doi.org/10.1016/S0167-6245(01)00054-3

Salleh, N. A., Rohde, F., \& Green, P. (2017). Information Systems Enacted Capabilities and Their Effects on SMEs' Information Systems Adoption Behavior. Journal of Small Business Management, 55(3), 332-364. https://doi.org/10.1111/jsbm.12226

Salmeron, J. L., \& Bueno, S. (2006). An information technologies and information systems industry-based classification in small and mediumsized enterprises: An institutional view. European Journal of Operational Research, 173(3), 1012-1025. https://doi.org/10.1016/j.ejor.2005.07.002

Serviço Brasileiro de Apoio às Micro e Pequenas Empresas [Brazilian Micro and Small Business Support Service] (2014) Participação das Micro e Pequenas Empresas na Economia Brasileira [Participation of Micro and Small Enterprises in the Brazilian Economy]. Retrieved from: http://www.sebrae.com.br/

Tan, K. S., Chong, S. C., Lin, B., \& Eze, U. C. (2010). Internet-based ICT adoption among SMEs. Journal of Enterprise Information Management, 23(1), 27-55. https://doi.org/10.1108/17410391011008897

Tajudeen, F. P., Jaafar, N. I., \& Ainin, S. (2018). Understanding the impact of social media usage among organizations. Information \& Management, 55(3), 308-321. https://doi.org/10.1016/j.im.2017.08.004

Thong, J. Y. L. (1999). An Integrated Model of Information Systems Adoption in Small Businesses. Journal of Management Information Systems, 15(4), 187-214. https://doi.org/10.1080/07421222.1999.11518227 
Upadhyay, P., Jahanyan, S., \& Dan, P. K. (2011). Factors influencing ERP implementation in Indian manufacturing organisations. Journal of Enterprise Information Management, 24(2), 130-145. https://doi.org/10.1108/17410391111106275

Yin, R. K. (2009). Case Study Research: design and methods. United Kingdom: SAGE Publications.

Zilber, S. N., \& Araújo, J. B. (2012). Small Companies Innovations in Emerging Countries: E-Business Adoption and its Business Model. Journal of Technology Management \& Innovation, 7(2), 102-116. https://doi.org/10.4067/S0718-27242012000200009

Zondi, W. B. (2017). Challenges Facing Small Business Development in South Africa. International Journal of Economic Perspectives, 11(2), 621628.

Zorpas, A. (2010). Environmental management systems as sustainable tools in the way of life for the SMEs and VSMEs. Bioresource Technology, 101(6), 1544-1557. https://doi.org/10.1016/j.biortech.2009.10.022 